\title{
Collective Living and Universal Housing Design Concepts towards Self-Sufficient Community
}

\author{
Harlina Mohamad Ali, Mazuiyah Mohd Dom, \\ Muhamad Shamin Sahrum \\ Centre of Studies for Architecture Faculty of Architecture, Planning \& Surveying, \\ Universiti Teknologi, MARA, Malaysia \\ harlinaali@yahoo.co.uk, harli895@salam.uitm.edu.my,
}

\begin{abstract}
The idea of self-sufficient community develops as the awareness of protecting the environment arises. Due to the differences in socio-cultural backgrounds, a community could become less cohesive. Thus, communal- based activities should be implemented in a community to inculcate community spirit and to promote collective living. To achieve this, housing schemes should be provided with collective spaces for deßned communal activities. Universal Housing Design principles can be implemented to the layout plans, where the needs of diverse people and abilities over time are addressed. The paper advocates collective living strategies and Universal Housing Design principles towards achieving a self-sufßcient community.
\end{abstract}

Keywords : self-sufßcient community; collective living; green initiatives; universal housing features.

eISSN 2514-751X @ 2018. The Authors. Published for AMER ABRA cE-Bs by e-International Publishing House, Ltd., UK. This is an open-access article under the CC BY-NC-ND license (http://creativecommons.org/licenses/bync-nd/4.0/). Peer-review under responsibility of AMER (Association of Malaysian Environment-Behaviour Researchers), ABRA (Association of Behavioural Researchers on Asians) and cE-Bs (Centre for EnvironmentBehaviour Studies), Faculty of Architecture, Planning \& Surveying, Universiti Teknologi MARA, Malaysia. https://doi.org/10.21834/aje-bs.v3i8.276 


\subsection{Introduction}

For the future, the notion of self-sufficient community is the answer for the protection of the environment and ecological systems. The increase in human population is inevitable and thus the consumption of natural resources increases too. Social and cultural issues go in tandem with the growth of population. Society tends to become less cohesive due to clash of backgrounds, unfamiliar traits and different customs. In order to achieve a self-sufficient community, the community must also be cohesive. The community's well-being is important to be addressed and can be achieved through a more conducive living environment. The identification of practical green initiatives that promote collective living can be implemented in a community as ritual everyday activities. This will inculcate community spirit while advocating the notion of saving the planet as a common cause. Housing development is the most recognized representation of a community as it generates the population. Housing development should be provided with quality spaces for defined community activities as it encourages socio- cultural integration.

\subsection{Literature Review}

\subsection{Past, Present and Future Issues}

Collective living and more sustainable lifestyles in their daily lives had been common practice for people of past communities. The life of Malaysian society back then was rooted in strong cultural backgrounds, evolving around agriculture-based activities and close-knit communities. Yahya (2003) noted that the concepts of sharing and cooperation were fundamental to the Malay culture and to the traditional Malay lifestyle, as well as the general preference for community intimacy over personal privacy.

As Malaysians become more affluent, the socio-cultural dynamics has shifted as Malaysia moves towards being a technology-based society. There is mounting evidence that human settlements have a detrimental impact on the environment and ecological systems. There is awareness towards self-sufficient living, and it is growing particularly in the West. In order to reduce the carbon footprint, earth-friendly practices are heavily-advocated. Svensson (2012) argued that socio-cultural dispositions, material culture and collective action need to be included in future strategies for creating more sustainable lifestyles.

There is a growing need to rethink how people live and sustain themselves within the urban environment of the future. Rapid urbanisation brings more and more people from the rural areas to large cities. World population is expected to grow from 6.7 billion to 9.2 billion between 2007 and 2050; virtually all of the 2.5 billion increases will occur in the developing world's urban areas (UNDESA, 2008). This massive migration to urban areas could also lead to the issue of insufficient food supply in the future. The supply of food sources continues to be unstable due external factors such as climatic conditions, natural disasters and hostilities. The increase in food prices is unavoidable. An alternative living scheme need to be materialised in order to live more self-sufficiently for future communities. 


\subsection{The Definitions of Self-sufficient Community and Collective Living}

The definition of being self-sufficient is being able to fulfill one's own needs without help from others while the term community means people living in one place, like district or city and considered as a whole (Oxford Advanced Dictionary, 2001). Fraga and Burg (2006) elaborated that an area of the city is self-sufficient when it has a variety of activities and design should make emphasis on dense, collective and complexity of activities. This paper looks into the characters of self-sufficient housing as an independent entity that advocates collective living but at the same time relates back to the neighbouring context and the city as a whole. A self-sufficient dwelling is one that is connected to the local system and knows how to respond to the social, cultural, technical and economics of its surroundings (Guallart, 2006). Meanwhile, collective living refers to a group or society as a whole that share responsibility, action and effort in their daily lives (Oxford Advanced Dictionary, 2001).

\subsection{Methodology}

This paper investigates the notion that collective living promotes solidarity and cohesiveness among the residents in a community. Qualitative method is applied in this research using unobtrusive and obtrusive methods. Unobtrusive method covers content analysis on existing theory, national housing policy and standard guidelines. Obtrusive method covers visual perception study on human behavioural pattern and case studies. The first case study is on a permaculture community which practises green strategies in their daily lives. In-depth interview is being conducted with the residents to understand the process and its implementation. Field work will be conducted by participating in workshops within the community. This paper viewed collective living from three (3) separate but interconnected strategies, i.e. from environmental approach, socio-cultural approach and spatial approach. The elaboration is as follows:

\subsection{Environmental Approach}

Environmental approach is seen as activity-based community projects based on green strategies. Among the activities that can be done collectively include ediblegardenand organic farming through permaculture techniques, seeds and organic fertilizers produced through cooperatives, rainwater harvesting, composting and mulching, recycling, community parks, etc. The benefits of belonging to a community garden, in addition to the social aspect, include improved mental health, improved physical health through exercise, improved diet through an increase in fresh vegetables and fruits intake as well as appreciation of other cultures and their cuisines (Millen, 2006). In Malaysia, organic farming through permaculture design principles is taking shape nicely in rural settings such as in Embun Pagi, Batu Arang, Selangor pioneered by Sabina Arokiam. Permaculture is a system to design human settlements and agriculture systems mimicking those in natural ecologies. Permaculture can be practised in urban areas and is essentially common sense living, which means using the resources available to the fullest. This include intensive small scale gardening, recycling and container planting (Millen, 2006). 
In 2008, the Federal Government of Malaysia initiated the Green Planet Programme (Dasar Bumi Hijau) to promote collective living within urban communities. Edible gardens are cultivated on patches of land offering freshly grown produce either for consumption or sold by cooperative of farmers and gardeners in housing development. Self cultivation and the idea of collective living are inseparable. Growing one's own food ensures food security and that domestic demand is met, even if the market's food supply is unsteady.

\subsection{Socio-cultural Approach}

Collective living can also be done through activities which are humanistic oriented. This includes community policing or Rukun Tetangga in the Malaysian context which promotes crime prevention, security for the community and solidarity among the residents. A community childcare centre which is run by the local residents, encourages the culture of looking out for each other. Religious oriented activities strengthened one's beliefs and brotherhood and centred on places of worship. In Islam, the mosque or surau is also a community center where one goes to pray, learn, socialise, and at times used as a pre-school or orphanage. Community kitchen is also part of collective living strategy where social and religious events can be organised. The idea of community kitchen can be done weekly or even on a daily basis where a group of residents in the community participates to cook for the community. This will encourage community participation that enhance social interaction, improve communication and creates a friendly environment among the residents. It is also a concept, practiced widely in co-housing development in the West. Residential development should include recreational facilities such as a community park which includes children playing area, playing field, sports courts, exercise apparatus, etc. The playing area for children should allow easy surveillance from the parents through "eyes on the street" concept. This is to ensure that the safety of the children is assured and to prevent any untoward incidents.

\subsection{Spatial Approach}

Collective living in terms of spatial approach means investigating how communal spaces or "space collective" can be shared by the dwellers in a community but at the same time their private domain or personal sphere are protected. "Space collective" refers to common spaces within the housing complex that aims at giving the neighborhood a new spring through both strong and suitable contemporary architectural and urban intervention that benefits the community (MDW Architecture, 2010). The degrees of territoriality are assimilated, and defensible space becomes a reality within the community. Defensible space theory is about spaces that are intentionally designed to be supervised, either directly or indirectly in order to maintain safety and security (Newman, 1973). People will only defend the spaces if they take pride in the spaces and claim territoriality over it. Once the "sense of belonging" is attached to the place, they will automatically defend the space from being intruded by strangers (Abbas, 2000). The new dwelling culture that is emerging sees the residence widening towards shared, semiprivate and public spaces that hosts activities directed to the neighborhood; and these inter-residential quality spaces help strengthen neighborly relations, social as well as cultural bonds (Cocco and Pibiri, 2006). 


\subsection{The Concept of Universal Housing Design}

According to Universal Housing Development Guidelines (Australian Standard, 2008), Universal Housing Design refers to homes that are practical and flexible which meets the needs of people of different ages and abilities over time. This type of design incorporates key easy living features that aim to make homes accessible and adaptable. It enhances the quality of life for all levels of occupants including single person, people with disability, old age pensioners, people with temporary injuries and family with young children. Universally designed housing is an approach to building homes which is well integrated within the community with living spaces that meet the current and future needs of home occupants. It is an inclusive design philosophy which enhance the design of products, services and environments.

In the 20th century, the concept of Universal Design was developed in the United States which was driven by the human rights of injured soldiers returning from wars, the needs of older people and people with disabilities (Follete, 1998). This term is also known as 'Design For All', 'Life Span Design' and 'Inclusive Design'. The United Kingdom 'Lifetime Homes, Lifetime Neighbourhoods Strategy' announced in 2008 includes the Lifetime Homes Standard (a Universal Housing standard) in its Codes for Sustainable Homes (Nissim, 2008). The strategy includes a plan for all public and private housing to be built according to that Standard by 2013. The Australian Standard for Affordable Housing (AS2499) has been developed using Universal Housing Design Guidelines. It includes Key Design Features and Good Practices towards adaptable and accessible dwelling design (Newman, 2011). It stated that Universal Housing Design offers universal benefits that not only strengthening social inclusion and improving recognition of human rights, but also highlighting significant social and economic benefits.

\subsection{Universal Housing Design Principles}

According to a study by The Centre for Universal Design at North Carolina State University (1998), among the principles of Universal Housing Design are as follows :

1) Equitable to use :

Housing design should be useful, appealing and marketable to all potential home occupants with diverse ability.

2) Flexible in use :

Housing design and products selection should accommodate a wide range of individual preference and abilities.

3) Simple and intuitive to use :

Housing design and layout should accommodate all home occupants regardless of their past experiences, familiarity or cognitive ability.

4) Easy to interpret :

Housing design should communicate environmental information to the home occupant, regardless of ambient conditions or the user's sensory abilities.

5) Safe and sensible to use :

Housing design minimises hazards and adverse consequences of unintended actions. 
6) Requires low physical effort :

Housing design and product should be easy, comfortable and efficient to use to accommodate a wide range of individual preferences and abilities.

7) Promotes ease on approach to housing features and elements :

Living spaces are designed to ensure that sufficient area is provided in order for the house occupants to easily approach and manipulate the elements within their home environment.

\subsection{Analysis and Findings through Design Proposal}

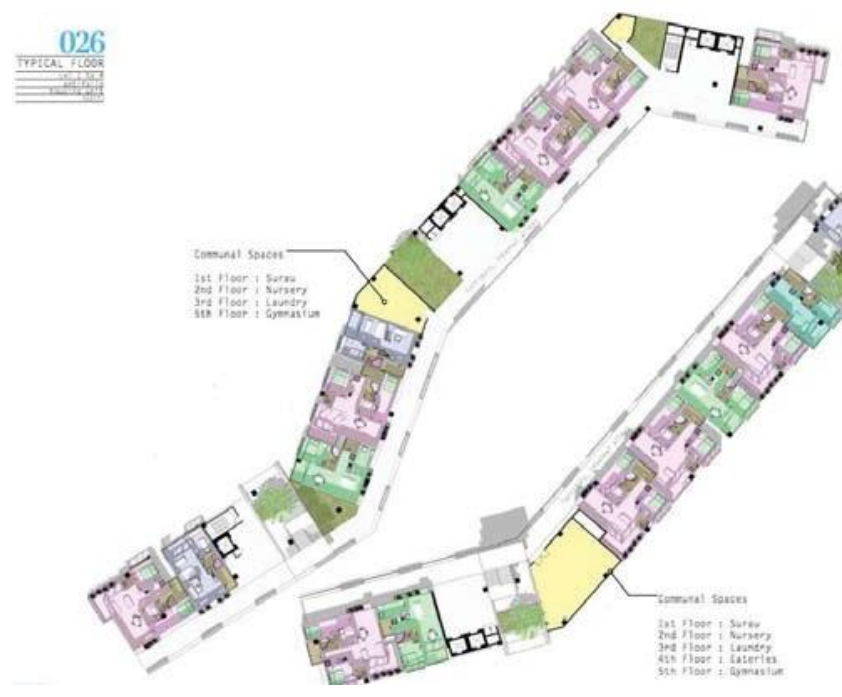

Figure 1: Proposed Layout Plan

(Source: Muhamad Shamin, 2012).

The collective living strategies through environmental, socio-cultural and spatial approaches discussed earlier in the Methodology section are applied in this design proposal. The public spaces within the housing block are every bit as important as the habitable spaces. The public spaces are the communal spaces or "space collective" which is designed to be at every floor and is intended for community cohesion. The floors are vertically and horizontally connected. On various levels there are programmatic spaces intended to provide residents with the necessary facilities for eventful collective living such as religious centres, eateries, nursery and gymnasium which are all connected by "vertical gardens" accessible via staircases and lifts. 


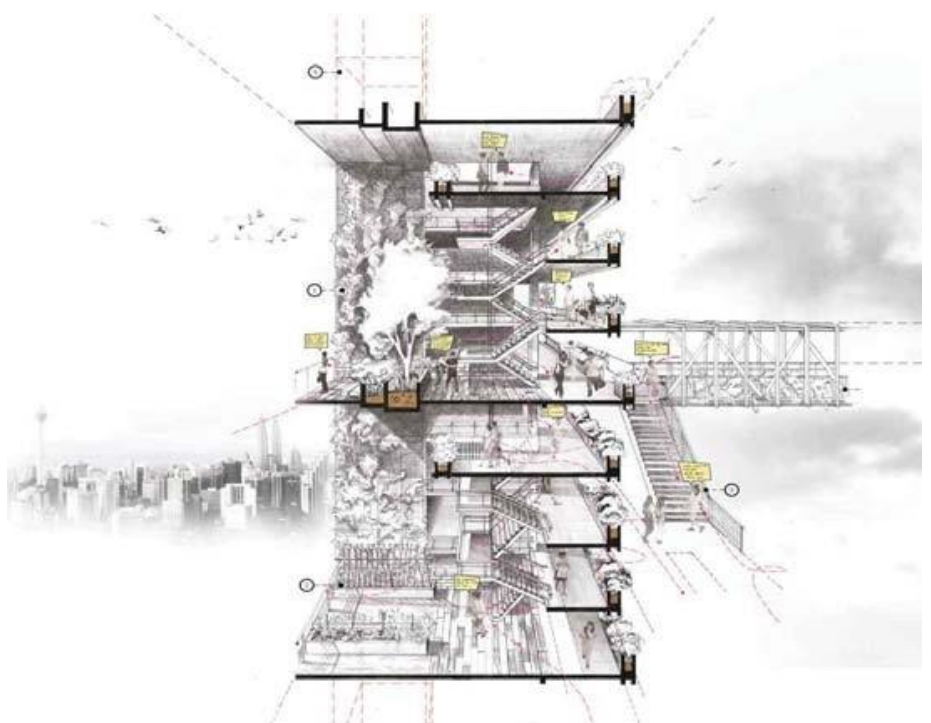

Figure 2: Proposed Sectional Perspective

(Source: Muhamad Shamin, 2012).

In this design proposal, vertical voids are placed at every four floors. In vertical dwellings, circulation is the main pulse running throughout the building. Thus, it seems only logical for the public spaces to be positioned where interaction between residents would occur most. A large central void acts as a main node located at various points in the building and accommodates a "vertical garden" in the multi-storey housing. Corridors of different floors will run adjacent to this void, providing visual retreat away from the monotonous rows of doors into one of green sceneries. Each of these voids could have a different function. On one void, an edible community garden could be established, while on another, a community park.

The cultivation of the edible community garden adopts permaculture technique that promotes ahealthylifestyleamong the residents. The concept of the edible community garden extends to the common corridors. This is one of the collective living strategies that enhance solidarity among the residents. By using Universal Housing Design principles, each living unit is connected by ramp at the main entrance for easy access. The internal layout of the living unit is comfortably spacious, accessible and accommodates people of diverse abilities over a period of time. Each living unit is equipped with a vestibule, yard and verandah which will facilitate the edible gardening activities. 
Mohamad Ali, H., et.al. / Asian Journal of Environment-Behaviour Studies (ajE-Bs), 3(8) May / Jun 2018 (p. 23-32)

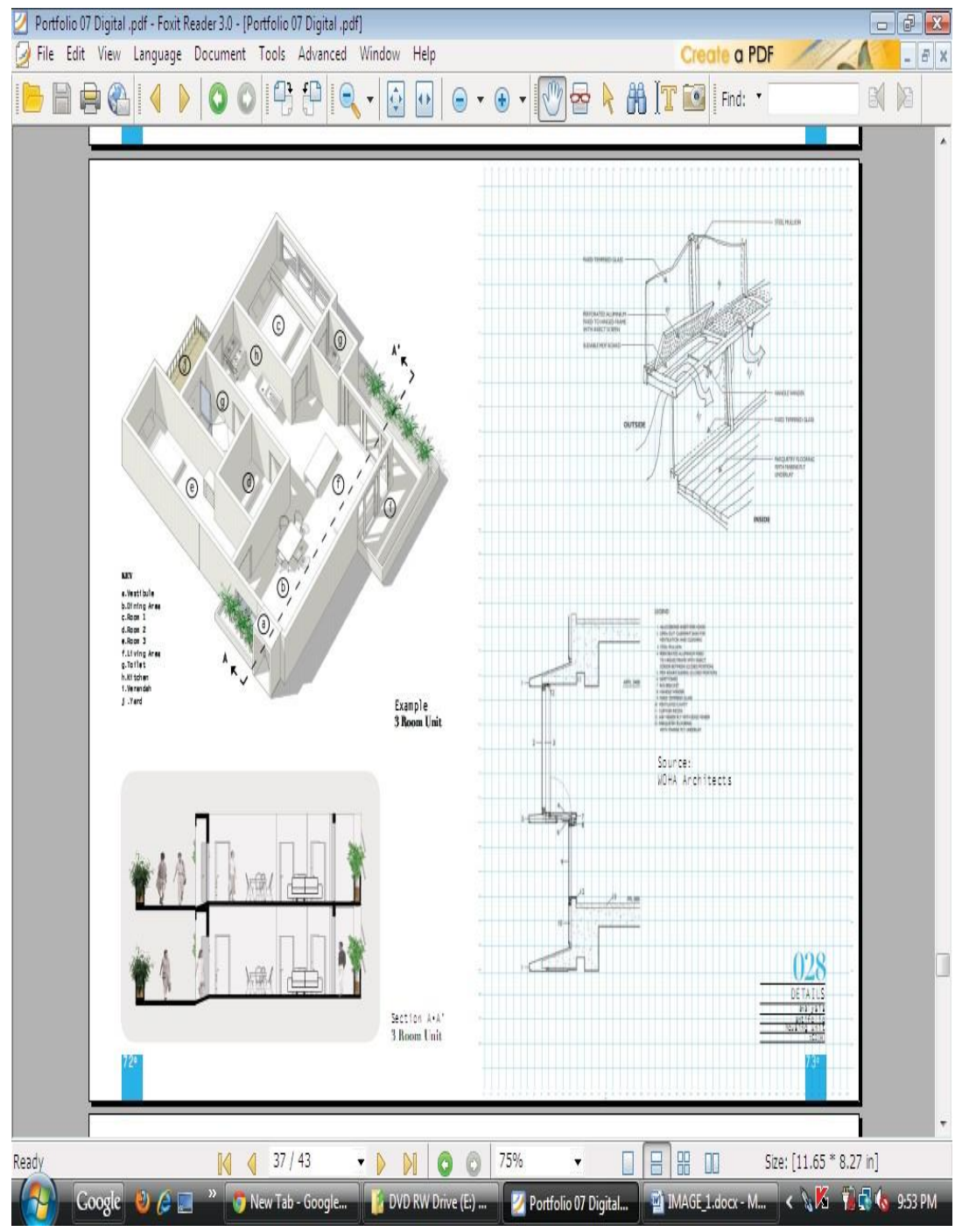

Figure 3: Axonometric View and Section of Typical House Unit (Source: Muhamad Shamin, 2012). 


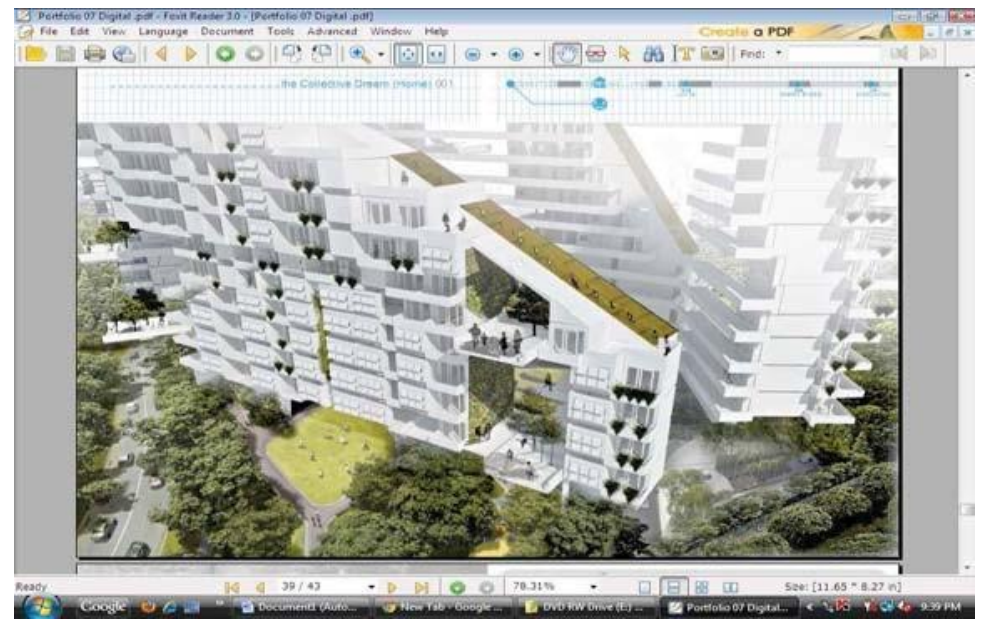

Figure 4: Perspective View of the Design Proposal

(Source: Muhamad Shamin, 2012).

\subsection{Conclusion}

The idea of a cohesive community relates to the notion of feeling belonged. The sense of belonging to a place is important. Feeling belonged means to have a personal relationship with the place of being and to be part of the neighborhood. Chuan, et al (2010) reported that among the influences that dictate the decision to purchase houses in the Klang Valley in Malaysia are neighborhood quality living and community living environment. This is because Malaysian households prefer to reside longer in one familiar neighborhood. Chuan, et al added that residents are psychologically secured when trustworthy neighbors are around. Thus, collective living strategies and Universal Housing Design principles are ideal to be introduced in achieving a more self-sufficient community in the future. The potentials of the new ideas put forward in this paper for the betterment of future communities from the socio-cultural and environmental perspectives is promising and exciting.

\section{Acknowledgement}

The authors of this paper would like to thank Research Management Institute (RMI), Universiti Teknologi MARA for awarding them the Research Intensive Fund (RIF) grant to pursue this research. The authors wish to acknowledge an expanded version of this paper is available in Procedia - Social and Behavioral Sciences. 


\section{References}

Abbas, M.Y. (2000). Proxemics in Waiting Areas of Health Centres: A Cross Cultural Study (PhD. Thesis. U.K.:The University of Sheffield).

Chuan, S. et al. (2010). House Purchasing Decisions: A Case Study of Residents of Klang Valley, Malaysia.

Coco, F.N. \& Pibri, R. (2010). Sharing in Collective Living. In C3, No.329. Seoul:C3 Publishing Co.

Fraga, R. \& Burg, O.T. (2006). Urban Sustainable. In Self-Sufficient Housing - IAAC First Advanced Architecture Contest. Catalonia: IAAC+Actar.

Follete, M. (1998). Design Research and Methods Journal. The Centre for Universal Design, North Carolina State University.

Guallart, V. (2006). Self-Sufßcient Habitat. In Self-Sufficient Housing -IAAC First Advanced Architecture Contest. Catalonia:IAAC+Actar.

Housing \& Local Government Ministry. (2008). Pekeliling Ketua Setiausaha Kementerian Perumahan dan Kerajaan Tempatan Bil. 5 Tahun 2008 - Pelaksanaan Program Bumi Hijau oleh PBT, unpublished.

Nissim, R. (2008). Lifetime Homes, Lifetime Neighbourhoods Strategy.

UK Lifetime.

MDW Architecture. (2010). Le Lorrain Residential Complex. In C3, No.329. Seoul: C3 Publishing Co.

Millen, T. (2006). Greening the Planet, One Backyard at a Time. In Ecos, issue Aug-Sept 2006, 132, pg 30-31. CSIRO Publishing.

Newman, O. (1973). Defensible Space: People and Design in the Violent City. London: Architectural Press.

Newman, R. (2011). Australian Standard for Affordable Housing (AS2499). Oxford Advanced Dictionary. (2001). Oxford University Press.

Svensson, E. (2012). Achieving Sustainable lifestyles? Socio-cultural Dispositions, Collective Action and Material Culture as Problems and Possibilities. Journal of Local Environment, Mar2012, Vol. 17 issue 3, pg 369-386.

UNDepartment of Economic and Social Affairs (UNDESA). (2008). World Urbanization Prospects: The 2007 revision, executivesummary, United Nations, New York.

Yahya, A, (1998). The Kampong. InChen VoonFee (ed), the Encyclopedia of Malaysia - Architecture. Kuala Lumpur: Archipelago Press. 